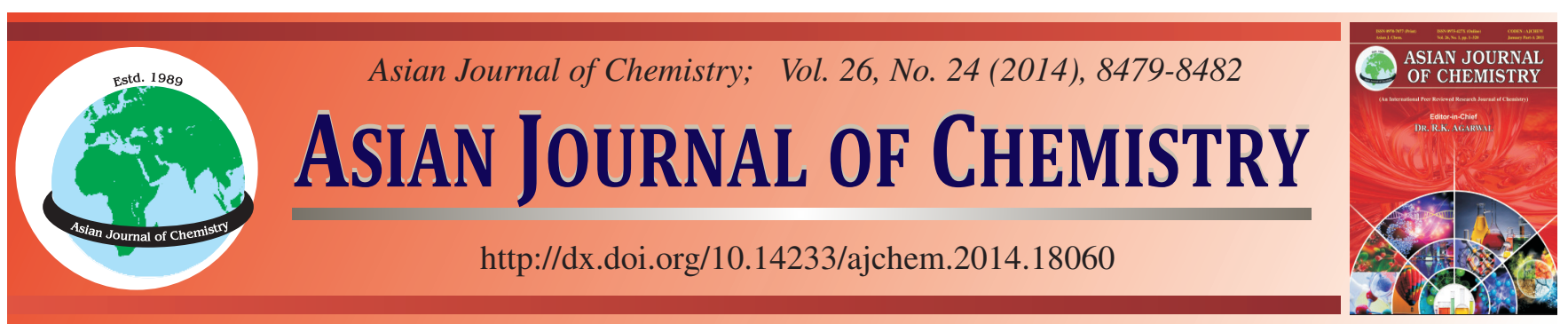

\title{
Quantitative Assessment of Cefuroxime: A Second Generation Cephalosporin in Pharmaceutical Formulations and Spiked Plasma Using Ultra Performance Liquid Chromatography-Tandem Mass Spectrometry
}

Masoom Raza Siddiqui ${ }^{1}$, Saikh Mohammad Wabaidur ${ }^{1, *}$, Zeid A. Alothman ${ }^{1}$, Moonis Ali Khan ${ }^{1}$ and Mohammad Shamsul Ola ${ }^{2}$

${ }^{1}$ Advanced Materials Research Chair, Chemistry Department, College of Science, King Saud University, Riyadh, Saudi Arabia

${ }^{2}$ Department of Biochemistry, College of Science, King Saud University, Riyadh, Saudi Arabia

*Corresponding author: Fax: +966 14675992; Tel: +966 14674198; E-mail: tarabai22@yahoo.com.sg

\begin{abstract}
A simple and rapid method has been developed for the determination of cefuroxime in pharmaceutical formulations and spiked plasma. The method involves the application of ultra performance liquid chromatography-tandem mass spectrometry (UPLC-MS/MS) for the quantitative assessment of cefuroxime. The chromatographic separation of the cefuroxime was carried out using BEH $\mathrm{C}_{18}$ column (100 $\mathrm{mm} \times 2.1 \mathrm{~mm}, 1.7 \mu \mathrm{m}$ particle size) using a binary mobile phase mixture of 1-octane sulfonic acid sodium salt $\left(5.78 \times 10^{-4} \mathrm{M}\right)$ and acetonitrile $(50: 50, \mathrm{v} / \mathrm{v})$ at a flow rate of $0.5 \mathrm{~mL} \mathrm{~min}^{-1}$. The UPLC-MS/MS have shorter analysis time of $1 \mathrm{~min}$ was found to be linear over the concentration range of $0.5-5 \mu \mathrm{g} \mathrm{mL}{ }^{-1}$. Limit of detection and limit of quantitation of the UPLC-MS/MS method was obtained to be 0.10 and $0.301 \mu \mathrm{g} \mathrm{mL}^{-1}$. The method was validated as per the ICH guidelines. The recovery studies suggest an excellent recovery of the procedure which was found in the range of $99.94-100.47 \%$ for the pharmaceutical formulation and 95.63 to $96.89 \%$. for the spiked plasma. The RSD range of the developed analytical procedure ranged from $0.90 \%-1.68 \%$ in intra-day studies and $1.42 \%-1.97 \%$, respectively.
\end{abstract}

Keywords: Cefuroxime, Ultraperformance liquid chromatography-tandem mass spectrometry.

\section{INTRODUCTION}

Chemically, cefuroxime is known as $(6 \mathrm{R}, 7 \mathrm{R})-3-\{[($ aminocarbonyl)oxy]methyl $\}-7-\{[(2 Z)-2-(2-f u r y l)-2-($ methoxy-imino) acetyl]amino \}-8-oxo-5-thia-1-azabicyclo-[4.2.0]oct-2-ene-2carboxylic acid. This semi synthetic cephalosporin is reported to work against a wide variety of disease causing bacteria thus comes under the category of broad spectrum antibiotics. This antibiotic was discovered by present day GlaxoSmithKline, marketed in 1978 and approved by US FDA in 1983.

Cefuroxime is recommended for infection such as chronic bronchitis, pharyngitis, meningitis and urinary tract infection ${ }^{1,2}$. One of the most important feature of this antibiotic is that it can cross blood-brain-barrier which is less common among the second generation cephalosporin ${ }^{3}$. This can be administered both orally as well as in parenteral dosage form ${ }^{4}$. Susceptible organisms against this cephalosporin are Neisseria gonorrhoeae, Escherichia coli, Moraxella catarrhalis, Borre-liaburgdorferi, Streptococcus pyogenes and Haemophilus influenza ${ }^{5}$. Cefuroxime is administered as cefuroxime axetil which converts to cefuroxime through hydrolysis by the intestinal cells esterases $^{6,7}$.
In the view of its importance in human life the correct dose must be administered for safe and proper action, for this the drug must be assayed through a proper and sensitive analytical method. The analytical methods prove the amount of drug claimed in the marketed formulation.

Some of the analytical methods are reported for the assay of cefuroxime in marketed formulations are HPLC ${ }^{8-10}$, spectrophotometry ${ }^{11-14}$, Capillary electrophoresis ${ }^{15}$, HPTLC ${ }^{16}$ and LC$\mathrm{MS} / \mathrm{MS}^{17}$. The current communication proposed a new simple and high through put analytical methods for the quantitative analysis of cefuroxime in pure and marketed products using UPLC-MS/MS with electro spray ionization (ESI) source in multiple reaction monitoring (MRM) mode was used. The developed methods are validated as per the ICH guidelines.

\section{EXPERIMENTAL}

Cefuroxime sodium and 1-octane sulfonic acid sodium salt, were obtained from Sigma-Aldrich, St. Louis, MO, USA. Acetonitrile was obtained from BDH. Zinacef, parenteral dosage form of cefuroxime was procured from the local market in Riyadh city of Saudi Arabia while Zymocef, a product from Venus remedies limited was procured from Indian market. 
Analytical instrumentation and separation conditions: The separation of cefuroxime was carried out by UPLC-MS/ MS system comprising of AQUITY TM ultra-performance liquid chromatography system and a triple quadruple mass spectrometer manufactured by Waters corp. Milford, MA, USA. The acquisition of data and quantification of samples were run using MassLynxTM NT 4.1 software with QuanLynx ${ }^{\mathrm{TM}}$ program (Waters Corp., Milford, MA, USA). An ACQUITY UPLC BEH $\mathrm{C}_{18}$ column $(100 \mathrm{~mm} \times 2.1 \mathrm{~mm}, 1.7 \mu \mathrm{m}$ particle size) were used in this study, the whole experiment was carried out at $25^{\circ} \mathrm{C}$. The conditions for the MS/MS detection are listed in Table-1.

\begin{tabular}{cc} 
TABLE-1 \\
UPLC-ESI-MS/MS CONDITIONS \\
\hline Items & Parameters \\
\hline Polarity & ESI $^{+}(\mathrm{V}$ mode $)$ \\
Capillary voltage $(\mathrm{KV})$ & 3.0 \\
Cone voltage $(\mathrm{V})$ & 35 \\
Extractor $(\mathrm{V})$ & 2 \\
R.F lens $(\mathrm{V})$ & 0.2 \\
Source temperature $\left({ }^{\circ} \mathrm{C}\right)$ & 120 \\
Desolvation temperature $\left({ }^{\circ} \mathrm{C}\right)$ & 300 \\
Desolvation gas flow $(1 / \mathrm{h})$ & 600 \\
Cone gas flow $(1 / \mathrm{h})$ & 60 \\
MS/MS range & $50-460 \mathrm{~m} / \mathrm{z}$ \\
\hline
\end{tabular}

Chromatographic condition: The optimum separation of cefuroxime was achieved on a $\mathrm{BEH} \mathrm{C}_{18}$ column $(100 \mathrm{~mm} \times$ $2.1 \mathrm{~mm}, 1.7 \mu \mathrm{m}$ particle size) using a binary mobile phase mixture of 1-octane sulfonic acid sodium salt $\left(5.78 \times 10^{-4} \mathrm{M}\right)$ and acetonitrile $(50: 50, \mathrm{v} / \mathrm{v})$ at a flow rate of $0.5 \mathrm{~mL} \mathrm{~min}^{-1}$. $5 \mu \mathrm{L}$ sample volume was injected for the quantitative analysis purpose.

Standard solution preparation: The standard solution of cefuroxime $10 \mu \mathrm{g} \mathrm{mL}-1$ for UPLC-MS/MS was prepared volumetrically.

Preparation of test solution: The test solution for the UPLC-MS/MS analysis was prepared by dissolving the content of zinacef $750 \mathrm{mg}$ (GlaxoSmithKline) and zymocef $750 \mathrm{mg}$ (Venus remedies Limited) vials in $750 \mathrm{~mL}$ milli Q water and finally taking $10 \mathrm{~mL}$ from this solution to be diluted in 11 milli Q water.

\section{RESULTS AND DISCUSSION}

Optimization of chromatographic and the mass condition: The analytical separation and ionization of cefuroxime in the UPLC-MS/MS system is significantly influenced by the concentration of the mobile phase. The selection of the mobile phase is an important aspect for improving the peak shape, sensitivity and shortening of run time for the analyte. Increasing the fraction of acetonitrile resulted in distortion of peak whereas; with a decrease in the acetonitrile concentration very much tailing appears in the peak. Gradient elution was also tried but the obtained results showed limitations of lower response and longer run time. The separation and ionization of cefuroxime was best achieved with octane- 1 sulfonic acid and acetonitrile in equal ratio. This run time is one of the shortest analysis times reported in the literature. The disolvation temperature and the source temperature were optimized and selected to give highest response to the analyte. Variations in the cone gas and disolvation gas flows were done in order to achieve the highest response of cefuroxime.

To adjust ESI conditions for detection of cefuroxime, it was dissolved in mlli $\mathrm{Q}$ water and infused into the ion source of the mass spectrometer to perform full scans in both positive and negative ion detection mode. The result from the experimental data showed that ion at $\mathrm{m} / \mathrm{z} 448$ was the main peak with the maximum signal intensity in positive ion mode. Fullscan spectra of cefuroxime and its fragmentation pathway are shown in Fig. 1. The transition $m / z 448 \rightarrow 213$ in positive electrospray ionization was chosen for quantitation of cefuroxime. Typical chromatogram of the standard sample and pharmaceutical formulation is shown in Figs. 2 and 3, respectively. The peaks appeared only after $0.48 \mathrm{~min}$ of the injection of sample leading to a great saving in the time of analysis and solvent consumption.

Method validation: The developed method was validated as per the international conference on harmonization (ICH) guidelines in terms of linearity, system suitability, precision, accuracy, limit of detection and limit of quantitation and recovery.

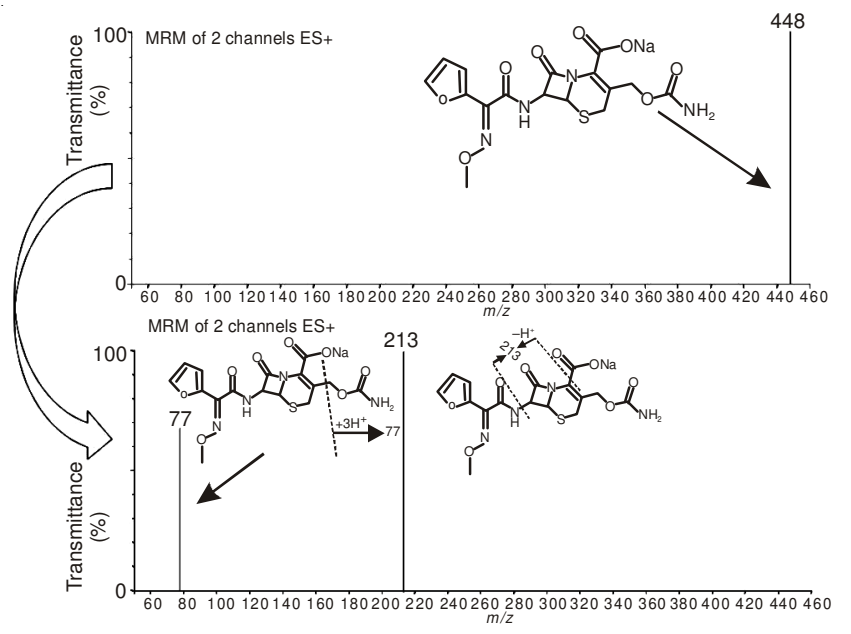

Fig. 1. Full scan product ion spectra of cefuroxime

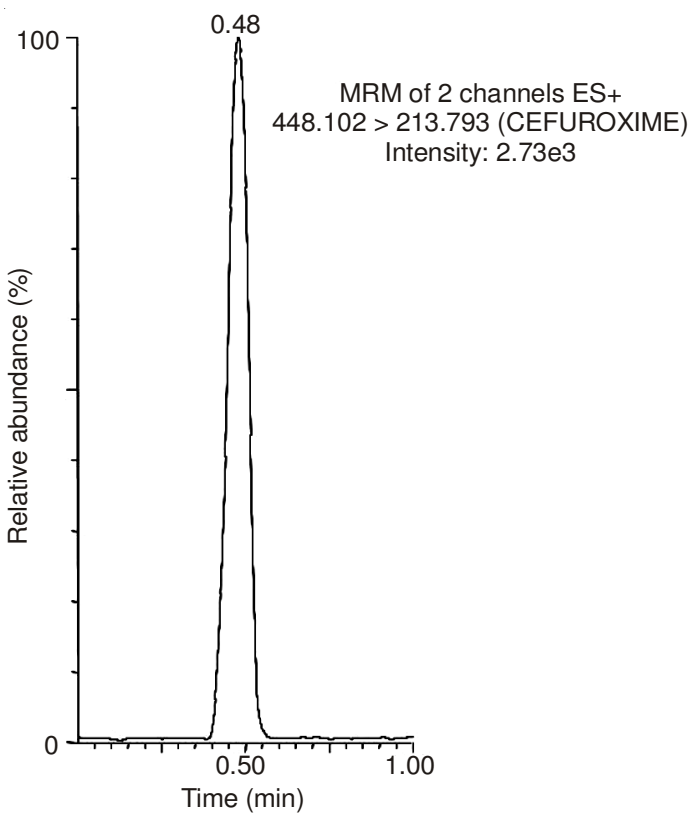

Fig. 2. Chromatogram of standard cefuroxime $\left(5 \mu \mathrm{g} \mathrm{mL}{ }^{-1}\right)$ using UPLC-MS/MS 




Fig. 3. Chromatogram of test solution of cefuroxime in formulation $(1 \mu \mathrm{g}$ $\mathrm{mL}^{-1}$ ) using UPLC-MS/MS

System suitability: System suitability test is an important parameter to ensure the performance of the analytical system. This important parameter should not be overlooked to ensure that the complete testing system including the instrument, reagents, columns are suitable for the analysis. Briscoe et al. ${ }^{18}$ described signal stability, response and carry over as the key component in the evaluation of the system suitability testing in UPLC-MS/MS. The signal stability and the response were checked by injecting 6 different samples of cefuroxime and the response was recorded. Result indicates stable peak height. The $\%$ RSD of peak area of 6 replicates standard solution (5 ppm) was less than $2 \%$ which indicate good performance. Further to check the carry over 6 blank samples were injected into the instruments and the results shows no carry over indicating decent performance of the system.

Linearity: Linear calibration plot was constructed in the UPLC-MS/MS procedure using six different concentration. It was observed that the procedure gave the reliable linear response in the concentration range of $0.5 \mu \mathrm{g} \mathrm{mL}^{-1}$ to $5 \mu \mathrm{g} \mathrm{mL}^{-1}$ when injected in triplicate.

Accuracy and precision: The difference between the observed value and the exact value is expressed in terms of accuracy the term accuracy and the precision are interlinked terms and accuracy have a very little significance if it lacks precision. As per the recommendation of $\mathrm{ICH}$ guideliens the accuracy and precision much be check at three concentration levels and in triplicate. In the current validation study accuracy was checked for both the interday and intra day assay as recovery assessment while precision was evaluated by repeatability and intermediate precision.

For the current UPLC-MS/MS method cefuroxime parenteral product equivalent to $0.5,3$ and $5 \mu \mathrm{g} \mathrm{mL}^{-1}$ were analyzed in five replicates at each of the three concentration points. Table- 2 shows the results of the recovery studies and the precision which is within the acceptable values.

Limit of detection and limit of quantitation: Limit of detection and limit of quantitation was determined by injecting 6 replicates of $0.01 \mu \mathrm{g} \mathrm{mL}{ }^{-1}$ test solution in the UPLC-MS/MS system. Height of the peak the cefuroxime in the chromatogram was recorded. After recording the cefuroxime peak 6 replicates of the blank solution was injected and noise was recorded and this $\mathrm{S} / \mathrm{N}$ ratio was calculated. The experimental value shows that the LOD and LOQ of the developed UPLC-MS/MS method were obtained to be $0.100 \mu \mathrm{g} \mathrm{mL}^{-1} 0.303 \mu \mathrm{g} \mathrm{mL}^{-1}$, respectively.

Validity of the proposed method: To ascertain the effect of the matrix and make the correction for the uncontrolled random error standard addition study was also performed during the current investigation. During this experiment in for UPLC-MS/MS pure amount of cefuroxime $\left(0.5 \mu \mathrm{g} \mathrm{mL}^{-1}\right)$ was added to it marketed formulation at three concentration levels of 2, 3 and $4 \mu \mathrm{g} \mathrm{mL}^{-1}$ then the nominal value of cefuroxime was calculated. The results of the standard addition experiments are mentioned in Table-3. Satisfactory recovery and lower RSD could be evident from the results in Table-3.

Analytical solution stability: All the analytical procedure must check for the solution stability using the proposed method after its storage at room temperature and in the refrigerated condition. Thus in the current investigation the stability samples were checked for cefuroxime content for $24 \mathrm{~h}$ at an interval of $6 \mathrm{~h}$ at room temperature and at refrigerated conditions. The data was recorded as the $\%$ change in cefuroxime concentration with respect to time zero. During the experiments it was observed that the cefuroxime degradation after $24 \mathrm{~h}$ at room temperature was less than $1.57 \%$ while at that of refrigerated condition showed degradation less than $0.59 \%$.

Preparation and quantitative determination of plasma sample: The pre-stored plasma samples were brought to room temperature before further processing. The plasma sample was subjected to centrifugation at $4000 \mathrm{rpm}$ for $10 \mathrm{~min}$. Drug equivalent to 1,3 and $5 \mu \mathrm{g} \mathrm{mL}^{-1}$ was pipetted into the polypropylene

TABLE-2

EVALUATION OF ACCURACY AND PRECISION OF THE PROPOSED METHOD BY INTER-DAY AND INTRA-DAY ASSAY

\begin{tabular}{|c|c|c|c|c|c|}
\hline \multirow{2}{*}{ Assay type } & \multicolumn{2}{|c|}{ Amount (ppm) } & \multirow{2}{*}{$\operatorname{RSD}^{\mathrm{a}}(\%)$} & \multirow{2}{*}{$\mathrm{SAE}^{\mathrm{b}}$} & \multirow{2}{*}{$\mathrm{CL}^{\mathrm{c}}$} \\
\hline & Taken & Found \pm S.D. ${ }^{\text {a) }}$ & & & \\
\hline \multicolumn{6}{|c|}{ UPLC-MS/MS } \\
\hline \multirow{3}{*}{ Intra-day assay } & 0.5 & $0.49 \pm 0.01$ & 1.19 & 0.002 & 0.007 \\
\hline & 3 & $3.03 \pm 0.05$ & 1.68 & 0.022 & 0.063 \\
\hline & 5 & $5.01 \pm 0.05$ & 0.90 & 0.020 & 1.056 \\
\hline \multirow{3}{*}{ Inter-day assay } & 0.5 & $0.5 \pm 0.01$ & 1.61 & 0.003 & 0.010 \\
\hline & 3 & $3.00 \pm 0.06$ & 1.97 & 0.026 & 0.073 \\
\hline & 5 & $5.01 \pm 0.07$ & 1.42 & 0.032 & 0.089 \\
\hline
\end{tabular}

${ }^{\mathrm{a}} \mathrm{Mean}$ for five independent analyses. ${ }^{\mathrm{b}} \mathrm{SAE}$ standard analytical error; ${ }^{\mathrm{C} C . L .}$, confidence limit at $95 \%$ confidence level and four degrees of freedom $(\mathrm{t}=2.776)$ 
TABLE-3

STANDARD ADDITION METHOD FOR THE DETERMINATION OF CEFUROXIME IN PHARMACEUTICAL FORMULATIONS

\begin{tabular}{|c|c|c|c|c|c|c|}
\hline \multirow{2}{*}{ Formulation } & \multicolumn{3}{|c|}{ Amount $\left(\mu \mathrm{g} \mathrm{mL} \mathrm{m}^{-1} \mathrm{ppm}\right)$} & \multirow{2}{*}{ Recovery (\%) } & \multirow{2}{*}{ RSD (\%) } & \multirow{2}{*}{ SAE } \\
\hline & Taken & Added & Found \pm S.D ${ }^{a}$ & & & \\
\hline \multicolumn{7}{|c|}{ UPLC-MS/MS method } \\
\hline \multirow{3}{*}{ Zinacef } & 2 & 0.5 & $2.50 \pm 0.029$ & 100.16 & 1.19 & 0.013 \\
\hline & 3 & 0.5 & $3.50 \pm 0.06$ & 100.09 & 1.78 & 0.027 \\
\hline & 4 & 0.5 & $4.50 \pm 0.05$ & 99.94 & 1.06 & 0.021 \\
\hline \multirow{2}{*}{ Zymocef } & 2 & 0.5 & $2.51 \pm 0.043$ & 100.47 & 1.71 & 0.019 \\
\hline & 4 & 0.5 & $4.50 \pm 0.057$ & 100.09 & 1.27 & 0.026 \\
\hline
\end{tabular}

tube $(10 \mathrm{~mL})$ and $2 \mathrm{~mL}$ acetonitrile was added for protein precipitation. The total content of the polypropylene tube was vortex mixed and again centrifuged at $4000 \mathrm{rpm}$ for $20 \mathrm{~min}$. Finally, the supernatant was collected and was subjected to UPLCMS analysis for quantitative determination. The recovery of the cefuroxime in plasma sample was found in the range of 95.63 to $96.89 \%$. The chromatogram is shown in Fig. 4.

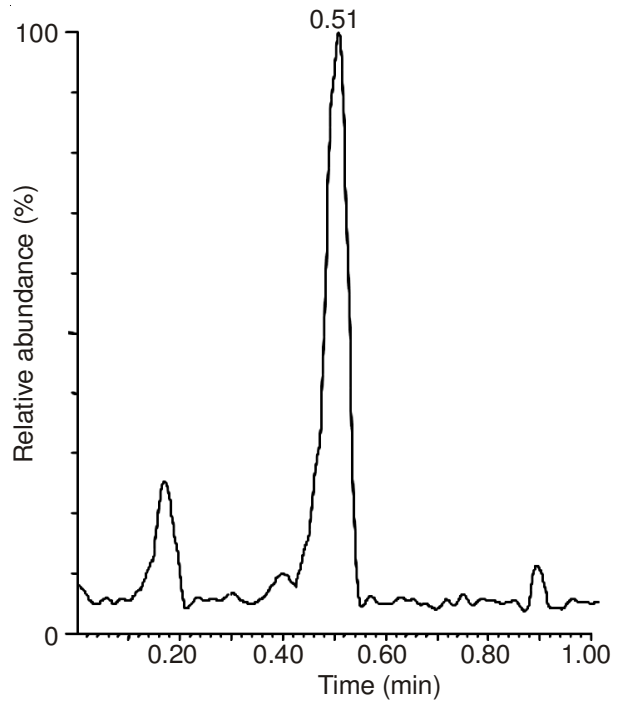

Fig. 4. Chromatogram of cefuroxime in spiked plasma $\left(1 \mu \mathrm{g} \mathrm{mL} L^{-1}\right)$ using UPLC-MS/MS

Applicability of the method: Applicability of the developed methods was checked by applying the method to the estimation of cefuroxime in its marketed formulation and in spiked plasma samples. Results show that the developed method is fast accurate and they do not require any pre-treatments prior to analysis except that of the plasma sample preparation. The current method will provide an alternative method for the quantitative analysis of cefuroxime in hospitals, research laboratories and the pharmaceutical industries.

\section{Conclusion}

The UPLC-MS method was developed for the analysis of drug cefuroxime in spiked plasma and marketed formulations. It was demonstrated during the experiments that even a small volume i.e. $5 \mu \mathrm{L}$ was sufficient for the rapid and accurate analysis and better sensitivity. from the standard addition study it was proved that no interferences from the matrix was found during the quantitative analysis.

\section{ACKNOWLEDGEMENTS}

The authors extend their appreciation to the Deanship of Scientific Research, College of Science Research Center, King Saud University, Riyadh, Saudi Arabia for supporting this project.

\section{REFERENCES}

1. C.R. Gelman, B.H. Rumakc and T.A. Hutchinson; Product Information, Ceftin ${ }^{\circledR}$, Cefuroxime Axetil. Glaxo Inc., Research Triangle Park, NC, USA, In: L DRUGEX® System; Micromedex Inc.: Englewood, CO, USA (1999).

2. C. Dollery, Therapeutic Drugs, Churchill Livingstone, London, U.K., edn 2 (1999).

3. Y.Y. Zhang, P.J. Wu and Q. Zhang, Zhonghua NeiKe ZaZhi, 28, 340 (1989).

4. M.S. Al-Said, K.I. Al-Khamis, E.M. Niazy, Y.M. El-Sayed, K.A. AlRashood, S. Al-Bella, M.A. Al-Yamani, A. Al-Najjar, S.M. Alam, R. Dham and Q. Zaman Qumaruzaman, Biopharm. Drug Dispos., 21, 205 (2000).

5. http://reference.medscape.com/drug/ceftin-zinacef-cefuroxime342500 .

6. M. Sasinoska-Motyl, I.W. Wisniewska and I. Gumulka, Acta Pol. Pharm., 52, 391 (1995).

7. R.D. Foord, Antimicrob. Agents Chemother., 9, 741 (1976).

8. M.R. Sengar, S.V. Gandhi, U.P. Patil and V.S. Rajmane, Int. J. Chem. Tech. Res., 1, 1105 (2009).

9. A. Szlagowska, M. Kaza and P.J. Rudzki, Acta Polon. Pharm. Drug Res., 67, 677 (2010).

10. G. Piva, D. Farin, I .Gozlan and R. Kitzes-Cohen, Chromatographia, 51, 154 (2000).

11. P. Jain, M. Patel and S. Surana, Int. J. Drug Develop. Res., 3, 318 (2011).

12. S. Shelk, S. Dongre, A. Rathi, D. Dhamecha, S. Maria and M.H.G. Dehghan, Asian J. Res. Chem., 2, 222 (2009).

13. M.D. Game, D.M. Sakarkar, K.B. Gabhane and K.K. Tapar, Int. J. Chem. Tech. Res., 2, 1259 (2010).

14. M.S. Elazazy and A. Shalaby, E-J. Chem., 9, 2261 (2012).

15. G. Pajchel and S. Tyski, J. Chromatogr. A, 895, 27 (2000).

16. K.R. Sireesha, D.V. Mhaske, S.S. Kadam and S.R. Dhaneshwar, Indian J. Pharm. Sci., 66, 278 (2004).

17. C.-C. Mondea, L. Vlase, A. Gyéresi and M. Bojita, Farmacia, 58, 408 (2010).

18. C.J. Briscoe, M.R. Stiles and D.S. Hage, J. Pharm. Biomed. Anal., 44, 484 (2007). 